Fecha de recepción: marzo 2015 Fecha de aceptación: junio 2015 Versión final: marzo 2016

\section{La escuela en escena: las películas como signos mediadores de la formación crítico-reflexiva de profesores ${ }^{1}$}

\author{
Mônica Ferreira Mayrink *
}

\begin{abstract}
Resumen: El objetivo de este artículo es discutir la forma como la imagen y, más específicamente, las películas, pueden constituir importantes signos mediadores de la formación de profesores. Tras una discusión inicial sobre el concepto de formación crítico-reflexiva, se discutirá sobre el valor de la imagen como una de las herramientas que predominan en la comunicación contemporánea, y se destacará el potencial del cine y de la ficción en general para crear oportunidades de construcción de nuevos conocimientos y vivencia de nuevas experiencias. Asimismo, se analizará el papel de signo mediador que pueden desempeñar las películas en la formación reflexiva de profesores. Para ilustrar los efectos de dichos signos en el desarrollo de la postura reflexiva de los docentes, se presentarán algunas evidencias del proceso vivido por profesores en un curso de formación inicial, resultante de su exposición a películas protagonizadas por profesores y alumnos que reproducen diferentes realidades escolares.
\end{abstract}

Palabras clave: formación de profesores - reflexión - películas - signo.

[Resúmenes en inglés y portugués en la página 51]

(*) Doctora en Lingüística Aplicada por la Pontificia Universidad Católica de São Paulo (PUC/SP). Profesora de la Facultad de Filosofía, Letras y Ciencias Humanas de la Universidad de São Paulo y de Posgrado en el Programa de Posgrado en Lengua Española y Literaturas Española e Hispanoamericana de la misma Facultad.

La práctica de la sala de clases cumple un papel primordial en la formación de profesores, pues allí los futuros docentes pasan por experiencias concretas de aprendizaje sobre qué es y cómo es enseñar. Sin embrago, este proceso de formación solamente se constituye como tal si se crean oportunidades efectivas de reflexión.

A lo largo de mi trabajo como formadora de profesores de lengua española en la enseñanza superior en Brasil he buscado maneras de contribuir a que los alumnos desarrollen una postura reflexiva que los conduzca hacia la toma de conciencia y la problematización de la práctica docente. El gran desafío que se presenta es la definición de los recorridos e instrumentos que se pueden utilizar para alcanzar tal objetivo. El uso de la imagen y, específicamente, de las películas, para favorecer el desarrollo de la postura reflexiva de 
profesores en formación (inicial o continuada) se ha mostrado particularmente eficaz y productivo en ese contexto.

El objetivo de este artículo es discutir sobre el uso de películas como recurso para el desarrollo de la capacidad reflexiva de profesores en formación inicial. Para presentar la perspectiva teórica que orienta mi práctica como formadora de profesores, partiré de una discusión sobre el concepto de formación crítico-reflexiva de profesores, con base en las contribuciones de Dewey (1933; 1938/1967), Schön (1983, 1987, 1992), Freire (1979), Kemmis (1987), Zeichner (1993) y Pimenta (2002). Enseguida, pasaré al análisis sobre el valor de la imagen como una de las herramientas que predominan en la comunicación contemporánea, y discutiré sobre el valor educativo del cine y de la ficción en general, debido a las oportunidades que crean para la construcción de nuevos conocimientos y vivencia de nuevas experiencias. Asimismo, analizaré el papel de signo mediador que pueden desempeñar las películas en la formación reflexiva de profesores, considerando la perspectiva de Vygotsky (1930/1998; 1934/1999). Para ilustrar los efectos de dichos signos en el desarrollo de la postura reflexiva de los docentes, presentaré algunas evidencias del proceso vivido por profesores en un curso de formación inicial, resultante de su exposición a películas protagonizadas por profesores y alumnos que reproducen diferentes realidades escolares.

\section{Aproximación al concepto de reflexión}

La definición del concepto de reflexión no se revela tan simple como pueda parecer. Pimenta (2002, pp. 18-19) señala que al hablar de profesor reflexivo, se corre el riesgo de vacilar entre el significado intrínseco y propio del adjetivo (ser reflexivo es un atributo propio del ser humano) y un concepto que forma parte de un movimiento teórico que pretende contribuir a la comprensión del trabajo docente. Así, la reflexión debe ser entendida como un camino que se debe desarrollar y recorrer hacia la comprensión del ser profesor y de su propia práctica pedagógica.

Los orígenes de la perspectiva de formación de profesores reflexivos remontan a Dewey. En su Teoría de las Experiencias, Dewey (1938/1967) evalúa la experiencia como un aspecto fundamental en la conformación del individuo. Para el autor, el individuo se constituye como tal debido a las interpretaciones que da a las experiencias por las que pasa, y esto se logra por medio del pensamiento reflexivo, cuya función reside en transformar una situación caracterizada por la oscuridad, duda, conflicto o perturbación en una situación clara, coherente, segura y harmoniosa. Sin embargo, la actitud de pensamiento reflexivo, conforme lo señala Dewey (1933), no se establece de manera natural, sino que debe ser desarrollada y cultivada, proceso en el cual la educación asume un papel fundamental.

Partiendo de esta perspectiva, el profesor puede desarrollar su capacidad reflexiva mediante prácticas que lo lleven a tomar conciencia del proceso de reflexión por el que está pasando y de las contribuciones que dicho proceso le puede proporcionar. Sin embargo, no podemos olvidarnos de un punto fundamental señalado por Dewey (1933, p. 16): el pensamiento reflexivo solo se concretiza cuando existe un deseo real de llevarlo a cabo. Si por un lado Dewey dejó las primeras contribuciones sobre qué es la reflexión, por otro, fue Schön $(1983,1987,1992)$ quien le dio mayor impulso al desarrollo de dicho concepto 2 . 
El autor identifica diferentes componentes de la práctica reflexiva: el conocimiento-en laacción, entendido como el saber hacer, conocimiento que se revela cuando desempeñamos nuestra acción de forma espontánea y hábil; la reflexión-en-la-acción (reflection in action), que se caracteriza por los pensamientos del profesor que lo llevan a improvisar, a tomar decisiones y actitudes en el mismo momento en que está trabajando en el aula, permitiéndole resolver los problemas con que se depara; y la reflexión-sobre-la-acción (reflection on action), que corresponde al momento en que el profesor piensa, retrospectivamente, sobre lo que ha hecho en su clase y descubre de qué forma su conocimiento-en-la-acción puede haber contribuido a alcanzar los resultados observados. En consecuencia, la reflexiónsobre-la-acción es un proceso consciente y deliberado, ya que el profesor analiza su propia acción en un momento posterior.

Buscando ampliar la propuesta de Schön, otros investigadores han añadido un componente crítico a la práctica reflexiva. Kemmis (1987), Zeichner (1993) y Contreras (2002), por ejemplo, destacan las relaciones entre la práctica individual y cotidiana del profesor, así como también ámbitos más amplios, institucionales y sociales, con implicaciones políticas y económicas.

En la base de esta perspectiva, se manifiestan algunos de los conceptos ampliamente discutidos en los trabajos de Freire (1979). El autor comprende la reflexión como un proceso que abarca las relaciones del hombre con el mundo y las transformaciones que pueden resultar de su participación activa en la sociedad. Para Freire $(1979$, p. 30), la primera característica de la relación del hombre con el mundo:

(...) es reflexionar sobre este mismo acto. Existe una reflexión del hombre frente a la realidad. El hombre tiende a captar una realidad, haciéndola objeto de sus conocimientos. Asume la postura de un sujeto cognosciente de un objeto cognoscible. Ello es propio de todos los hombres y no privilegio de algunos (por eso la conciencia reflexiva debe ser estimulada: conseguir que el aprendiz reflexione sobre su propia realidad) ${ }^{3}$.

La conciencia reflexiva, según Freire, hace posible para los hombres la reflexión crítica sobre sus propios actos. El autor sugiere diferentes estados de conciencia, entre los que se destaca la conciencia crítica, marcada por una visión indagadora que se propone analizar los problemas de forma profunda, que:

(...) no se satisface con las apariencias, (...) que busca verificar o probar los descubrimientos, (...) que es intensamente inquieto, (...) ama el diálogo, se nutre de este, frente a lo nuevo, no repele lo viejo por ser viejo ni acepta lo nuevo por ser nuevo, sino que los acepta conforme su validez (Freire, 1979, pp. $40-41)^{4}$.

Para Freire (1979), la conciencia crítica se caracteriza por la profundidad en la interpretación de los problemas, buscando principios causales, y le permite al hombre transformar la realidad. Así, lleva al profesor a la comprensión del contexto en que trabaja y a la toma de decisiones en un contexto mayor, que supera los límites de las paredes del aula. 
En cuanto al concepto de reflexión crítica, vale también destacar las contribuciones de Zeichner (1993) relacionadas a la enseñanza reflexiva como un proceso en el que la atención del profesor se dirige tanto a su propia práctica como a las condiciones sociales en que se sitúa dicha práctica. El autor entiende la reflexión crítica como una acción concreta, consciente y deliberada y valoriza, desde su perspectiva, la necesidad de que el profesor reflexione sobre su situación en el colectivo. Sus acciones deben, por lo tanto, vincularse a la situación de sus colegas, lo que permitirá el apoyo y el crecimiento mutuos.

Muy próxima a esta visión de reflexión crítica encontramos la perspectiva de Kemmis (1987), según la cual el profesor es quien analiza y cuestiona las estructuras institucionales en que se desempeña. Como resultado de este proceso crítico-reflexivo, el profesor puede llegar a comprender de qué forma dichas estructuras influyen en su modo de analizar y pensar su propia práctica, y puede también comprender sus implicaciones sociales y políticas. Según Kemmis, la práctica reflexiva se articula con un compromiso crítico que lleva al profesor a explorar la naturaleza social e histórica de su relación como un participante de las prácticas institucionalizadas de la educación y también de la relación entre su pensamiento y su acción educativa, conforme explica Contreras (2002, p. 163). Entendida de esta forma, la reflexión crítica alcanza una dimensión mucho más amplia, capaz de revelar el sentido ideológico de la enseñanza y de atribuir al profesor un papel fundamental de agente de cambios al darle la posibilidad de liberarse de los presupuestos, hábitos y costumbres impuestas por las instituciones e incorporados por él mismo, inicialmente, de manera acrítica.

El componente de transformación, presente en la definición del concepto de reflexión crítica de diferentes autores, es también destacado por Liberali (2010, p. 32), para quien:

La reflexión crítica implica la transformación de la acción, vale decir, la transformación social. No basta criticar la realidad, sino que hay que cambiarla, ya que individuos y sociedad son realidades indisociables. (...) al reflexionar críticamente, los educadores pasan a ser entendidos y a entenderse como intelectuales transformadores, responsables de formar ciudadanos activos y críticos dentro de la comunidad.

$\mathrm{Al}$ entrar en contacto con estas diferentes luces que se lanzan sobre la reflexión y la reflexión crítica parece quedar claro que en ninguna de ellas el desarrollo de la práctica reflexiva se revela como una tarea fácil, tanto desde el punto de vista del formador como del docente en formación.

El conocimiento de estas diferentes perspectivas nos permite comprender más claramente la formación del profesor crítico-reflexivo como un proceso de desarrollo de la capacidad reflexiva y de la conciencia crítica que se construyen en la relación con el otro y con el mundo, y que permite que el profesor cuestione, analice, interprete y comprenda su propia acción y la de otros, en el amplio universo institucional y social en que se introduce (Mayrink, 2007). En consecuencia, el profesor crítico-reflexivo llega a ser lo que es porque ha pasado por un proceso de desarrollo y perfeccionamiento de su capacidad de reflexionar críticamente sobre su propia acción y sobre la acción de otros profesores. Por ende, la reflexión crítica no constituye necesariamente un proceso natural, pues es un proceso más 
complejo que el simple pensar sobre la acción. Involucra conciencia, cuestionamiento, análisis y consecuente toma de decisiones que pueden generar transformaciones.

\section{El lugar de las películas en la formación reflexiva de profesores}

Pimenta (2002, p. 20) sostiene que "los currículos de formación de profesionales deberían propiciar el desarrollo de la capacidad de reflexión”. La autora concuerda con Perrenoud (2002, p. 33), que también apuesta en la necesidad de incorporar en la formación de profesionales reflexivos oportunidades para el desarrollo de la capacidad de reflexión durante la acción "mucho más de lo que hacemos espontáneamente". Por lo tanto, para estos autores la postura reflexiva necesita desarrollarse. Perrenoud (2002, p. 45) va más lejos al afirmar que "la práctica reflexiva se aprende mediante un entrenamiento intensivo". Una forma para lograrlo, propone el autor, obedece a la reestructuración del currículo de formación inicial, reservando tiempo y espacio para realizar un procedimiento clínico, con resolución de problemas, con el aprendizaje práctico de la reflexión profesional, de acuerdo a una articulación entre tiempo de intervención en campo y tiempo de análisis" (p. 44). Mayrink (2007) resalta la necesidad de desarrollar la capacidad reflexiva de los profesores para tornarla más espontánea y consciente, pero prefiere hablar de prácticas reflexivas y no de entrenamiento, término usado por Perrenoud (2002), pues la palabra sugiere un aprendizaje mecánico, como una simple repetición de acciones. Lo que se debe indagar en ambos casos es ¿qué recursos o instrumentos podrían usarse para realizar dichas prácticas? Entre las posibles formas de promover el desarrollo de la capacidad de reflexión se han usado tradicionalmente la observación de clases, la elaboración de diarios, el análisis de casos, la participación en debates, y las narrativas (Alarcão, 2003; Perrenoud, 2002; García, 1992). La propuesta que aquí presento reside en el uso de la imagen, específicamente, las películas, como elemento de mediación pedagógica para el desarrollo de la reflexión docente. Esta elección se justifica por varios motivos.

En primer lugar, es necesario recordar que la imagen es "una de las herramientas efectivamente predominantes en la comunicación contemporánea" (Joly, 1996, p. 10). Almeida (2001, p. 8) añade que "actualmente existe una significativa mayoría de personas cuya inteligencia fue y está siendo educada por imágenes y sonidos, por la cantidad y calidad del cine y televisión que ven". Para este autor, aun las personas que tienen más acceso al texto escrito, y para quienes "el texto escrito es siempre la referencia más importante, que permite volver, pensar, reflexionar (...) [están formando su] inteligencia del mundo a partir de las imágenes y sonidos de las producciones de cine y televisión”. (Almeida, 2001, p. 8) Como imagen, la película posee también características que la hacen un instrumento adecuado para la práctica de la reflexión. Desde el punto de vista didáctico, aparte de ser un recurso al alcance de la mayoría de los alumnos, puede generar elementos de discusión relevantes para la práctica pedagógica de los profesores en formación, ya que posee la capacidad para construir un mundo que mantiene relaciones complejas con el mundo real del aula. Así considerada, la película puede desencadenar una mirada reflexiva de los profesores en formación sobre las semejanzas o diferencias identificables entre la realidad del aula vivida por ellos y aquella que se presenta en la pantalla. 
De esta manera, aun cuando se considere mostrar una realidad que no es exactamente igual a la que se vive, la película constituye un tipo de imagen que "puede ser un instrumento de conocimiento porque sirve para ver e interpretar el propio mundo" (Gombrich,1971, en Joly, 1996, p. 60). El poder de la imagen como forma que tiene el hombre para comunicarse con el mundo es también objeto de discusión de Goyes, para quien la imagen es:

Un modo de representación (...) pero esta representación capturada por la percepción visual se distancia y/o se acerca a ese enmarañado de significados construidos al que llamamos realidad. Esta distancia que enfoca y 'desenfoca' lo que es real depende de los contextos mentales y sociales en los cuales viva el sujeto que los percibe. (Goyes, 2002, p. 8)

Como puede verse, el sujeto asume un papel fundamental en la atribución de significados para la imagen: "es el sujeto el que asemeja el contenido cultural de la imagen al contenido cultural del modelo original" (Goyes, 2002, p. 9). El "juego pedagógico" que se puede configurar en este caso, aclara Goyes (2002, p. 9), "se abre desde el querer saber lo que se ve, hacia la pregunta ¿qué vemos?, ¿qué miramos?”. De este modo, se abre el camino hacia la reflexión, hacia la re-lectura de la imagen (de la película) de acuerdo a la comprensión de mundo que caracteriza la realidad en que vive el sujeto.

Gomes (2004,p. 1) rescata este mismo pensamiento en la semiótica de Umberto Eco. Para él, comenta la autora, "el texto se compone de espacios en blanco que el lector ha de completar. Vive de la valorización de sentido que el destinatario ha colocado ahí". En lo que respecta al cine, alerta Gomes:

Cuya materia-prima la constituyen las imágenes, no se puede negar que existe una relación de comunicación entre espectador y película (...) La obra cinematográfica promueve un proceso comunicativo que guía a estos seres que se sientan en un sillón por horas a ejecutar un trabajo interpretativo y a atribuirle significación a la película. (Gomes, 2004, p. 4)

Según Andrew (1989, p. 194 en Gomes, 2004, p. 4), "las imágenes en sí mismas no poseen ningún significado, solo adquieren sentido en el contacto con el espectador. La búsqueda, el encuentro de algún significado en alguna película constituye de por sí un acto interpretativo".

En lo que respecta a la naturaleza de las películas utilizadas en prácticas reflexivas, podríamos pensar en tres tipos de videos a los que los profesores en formación podrían ser expuestos: a) grabaciones de sus propias clases; b) grabaciones de clases de compañeros; c) películas-ficción focalizadas en prácticas pedagógicas.

A pesar de que los dos primeros tipos de grabaciones (o películas) se sitúan más cerca de la realidad del profesor en formación, pues involucran directamente su propia práctica o la de sus compañeros, puede que estas no sean la mejor opción cuando lo que se busca es ofrecerle al profesor en formación una oportunidad tranquila para reflexionar sobre la práctica pedagógica. Ello se debe a que muchas veces el profesor se inhibe, se siente 
incómodo al dar observaciones sobre la clase de sus compañeros o simplemente no logra advertir, en sus propias imágenes o en las de sus condiscípulos, aspectos que podrían generar alguna reflexión sobre las clases que imparten. Aparecen así obstáculos que pueden comprometer el análisis y la discusión que se quiere realizar.

Por otro lado, la película-ficción es "una producción de la cultura, no de la pedagogía o de la didáctica" (Almeida, 2001, p. 7). En consecuencia, al exponer a los profesores "caricaturas" de clases, se promueve un distanciamiento saludable de aquel a quien se está observando (el personaje de la película), evitando así que los profesores en formación se sientan inhibidos para hacer críticas o manifestar ideas que no coincidan con la práctica pedagógica del personaje.

Aparte de esto, las películas-ficción pueden añadir una riqueza cultural a la formación de los profesores, ya que es posible encontrar producciones cinematográficas de diferentes procedencias. Dicha diversidad puede permitir un análisis comparativo de los contextos educativos en que se desenvuelven los personajes, al establecerse un puente con la realidad escolar brasileña. Como resultado, los futuros profesores pueden crecer en la comprensión del mundo pues, como señala Almeida (2001, p. 12), “ver películas, analizarlas, es (...) también el anhelo de entender el mundo por la producción artística del cine".

La propuesta que aquí se presenta se apoya en el trabajo con películas de tenor comercial, que de alguna forma enfocan el contexto escolar y las relaciones profesor-alumno, pero que no fueron producidas con objetivo didáctico o pedagógico. Por lo tanto, al usarlas como promotoras de reflexión, el intercambio de experiencias e ideas y la consecuente construcción y re-construcción de conocimiento, las películas ganan una nueva función mediadora, lo que nos remite a la teoría de Vygotsky, que "atribuía una importancia fundamental al concepto de actividad mediadora, aclarando que dicho concepto se refiere a varios tipos de mediación en la relación entre el individuo y la realidad, siendo el uso de herramientas y el uso de signos dos casos particulares de actividad mediadora" (Duarte, 2000, p. 209). A continuación, veremos cómo Vygotsky entiende los conceptos de herramienta / instrumento y de signo e intentaremos definir el papel que las películas desempeñan en la actividad que nos ocupa.

\section{Las películas: ¿instrumentos o signos mediadores?}

Vygotsky (1930/1998, p. 71) afirma que "la analogía básica entre signo e instrumento reposa sobre la función mediadora que los caracteriza”. Por otro lado, lo que distingue al signo del instrumento (o herramienta) es, de acuerdo al psicólogo, la forma como estos orientan el comportamiento humano:

La función del instrumento consiste en servir como un conductor de la influencia humana sobre el objeto de la actividad. El instrumento es orientado externamente y debe conllevar necesariamente a cambios en los objetos. Constituye un medio por el cual la actividad humana externa es dirigida para controlar y dominar la naturaleza. Por otro lado, el signo no modifica en nada el objeto de la operación psicológica. Constituye, asimismo, un 
medio de la actividad interna dirigido al control del propio individuo; el signo es orientado internamente. (Vygotsky, 1930/1998, pp. 72-73)

Desde el punto de vista de la estructura de las operaciones con signos, Vygotsky (1930/1998, p. 53) sugiere que:

Toda forma elemental de comportamiento presupone una reacción directa a la situación-problema enfrentada por el organismo -lo que puede representarse por la simple fórmula $(\mathrm{S} \rightarrow \mathrm{R})$. Por otro lado, la estructura de operaciones con signos requiere un eslabón intermediario entre el estímulo y la respuesta. Este eslabón intermediario es un estímulo de segundo orden (signo), colocado en el interior de la operación, donde asume una función especial: crear una nueva relación entre $\mathrm{S}$ y $\mathrm{R}$.

Vygotsky (1930/1998, p. 53) esclarece que el signo actúa sobre el individuo, que debe estar “activamente comprometido con el establecimiento de dicho eslabón (...). Consecuentemente, el simple proceso estímulo-respuesta es reemplazado por un acto complejo, mediado", que el autor representa con la siguiente figura:

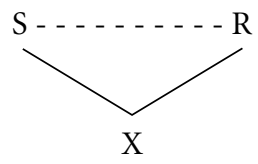

Figura 1. Representación del proceso de mediación (Vygotsky, 1930/1998, p. 53)

Así entendidas, las películas pueden caracterizarse como instrumentos o como signos, dependiendo del uso que se haga de ellas. Desde un principio, la mayoría de las películas comerciales se presentan originalmente como objeto de entretenimiento. Podríamos suponer que por lo general su efecto en el espectador es momentáneo y que satisface una necesidad específica del momento (la diversión). Bajo esta perspectiva la película cumple la función de instrumento, con una influencia meramente situacional en el espectador. Se puede decir además que, aunque las películas se propongan llevar al espectador a algún tipo de reflexión, esta no es necesariamente una reflexión sobre la práctica pedagógica, aunque la película esté ambientada en la escuela, en el aula o muestre la acción del profesor junto a sus alumnos. Para ejemplificar, tomaremos las sinopsis ${ }^{5}$ de dos películas que colocan la escuela en escena y que se podrían utilizar en cursos de formación de profesores:

Película 1: Cadena de Favores (Pay it forward, 2001, Warner Bros. Pictures)

Eugene Simonet (Kevin Spacey) es un profesor de estudios sociales cuya vida está en orden, con todo y todos en sus debidos lugares. Un día decide pedir un trabajo a sus alumnos. Trevor, (Haley Joel Osment) que está en este grupo, propone una especie de cadena 
del bien, en la que cada persona haría un favor a otras tres y estas a su vez harían lo mismo, sin pedir nada a cambio. El favor que cada uno presta debe ser algo grande, algo que la gente no puede hacer por sí misma. Con esto, Trevor intenta ayudar a su propia familia, que se reduce a su madre Arlene McKinney (Helen Hunt), una mujer valiente e industriosa, que trabaja en dos empleos y que lucha para criar a su hijo.

Una película sensible con un hermoso mensaje y una idea capaz de cambiar el mundo.

Como se ve, la sinopsis de esta película destaca el proyecto idealizado por el alumno Trevor y su potencial para cambiar el mundo. Vista y analizada desde este ángulo, se percibe que la trama de la película se centra en las consecuencias que conlleva el proyecto del muchacho en la vida de las personas, en sus relaciones familiares, en su propia constitución como individuo, que busca superar miedos y pertenecer a una familia feliz. La sinopsis no resalta la importancia de la figura del profesor o la naturaleza de la actividad que él demanda de los alumnos.

Película 2: Papá canguro (Daddy Day Care, 2003 - Columbia Tristar)

¡PAPÁ CANGURO es una divertida comedia sobre chicos traviesos que dominan la situación! En cuanto los publicistas Charlie (Eddie Murphy) y Phil (Jeff Garlin) pierden sus empleos tras intentar vender cereales matinales con sabor a legumbres, sus esposas vuelven al trabajo. Pero al percatarse de que ya no tienen condiciones financieras para mantener a sus hijos en la famosa Academia Chapman, dirigida por la terrible Señora Harridan (Angélica Huston), Charlie y Phil deciden montar la guardería del papá. ¡Aquí empieza la aventura de los dos padres haciendo las veces de niñeras!

En este caso, la sinopsis de la película destaca el lado cómico de las situaciones vividas por los personajes en su actuación como "niñeras"; en ningún momento se hace referencia al papel de educadores que los protagonistas acaban asumiendo. El tono de la comedia y la función de entretenimiento atribuida a la película se perfilan también en el comentario de un crítico de cine de Los Ángeles, impreso en la portada de la película: "Eddie Murphy y su grupo proporcionan diversión para toda la familia".

Como se ve, en ambos casos (películas 1 y 2), la actividad mediadora inmediata idealizada para las películas es el esparcimiento. Sin embargo, en cursos de formación docente se les puede dar otra función si se establece el objetivo de generar una reflexión sobre la práctica pedagógica. Así, las películas ganan un nuevo significado y una nueva función -la de signo- al hacer un uso consciente de estas, orientado a la reflexión sobre el quehacer docente. De este modo, el acto de ver la película puede venir acompañado de cuestionamientos que promueven una reflexión que busca extenderse más allá del momento en que el espectador (el profesor) ve la película. En consecuencia, se logra un efecto continuo (y no situacional y momentáneo) que contribuye a que los profesores hagan de la reflexión un componente permanente de su práctica docente diaria. Las películas como signos pasan, entonces, a ser mediadoras necesarias "al control del comportamiento humano y de los procesos mentales", como aclara Duarte. (2000, p. 209)

Entendido de este modo, el filme puede propiciar al profesor en formación la oportunidad de vivir una experiencia diferente, centrada en el otro, pero con una repercusión 
individual que enriquece y expande su continuo experiencial ${ }^{6}$. Sin embargo, no podemos desconsiderar la posibilidad de que, para algunos, la película siga siendo solamente un instrumento (de esparcimiento, por ejemplo), dependiendo del individuo y de la forma como se da su relación con esta.

El uso de la película como signo mediador en el contexto de formación de profesores puede ser comprendido a la luz de las redes de relación que se establecen en el proceso de mediación propuesto por Vygotsky. En este caso, $\mathbf{S}$ (la situación) corresponde al visionado y discusión de las películas, dentro del momento de formación por el cual pasan los profesores, momento que constituye el contexto más amplio, el trasfondo que caracteriza el escenario del proceso de mediación; $\mathbf{R}$ corresponde a la reflexión (crítica), reacción deseada, que se puede manifestar en forma de autorreflexiones y reflexiones compartidas; $\mathbf{X}$ (el signo mediador) corresponde a las películas, "estímulo auxiliar que facilita la complementación de la operación por medios indirectos". (Vygotsky, 1930/1998, p. 54)

De este modo, considerando el contexto de formación de profesores, es posible hacer una relectura de la estructura de operaciones con signos elaborada por Vygotsky (ver Figura 1), pasando a representarla por medio de las siguientes interrelaciones:

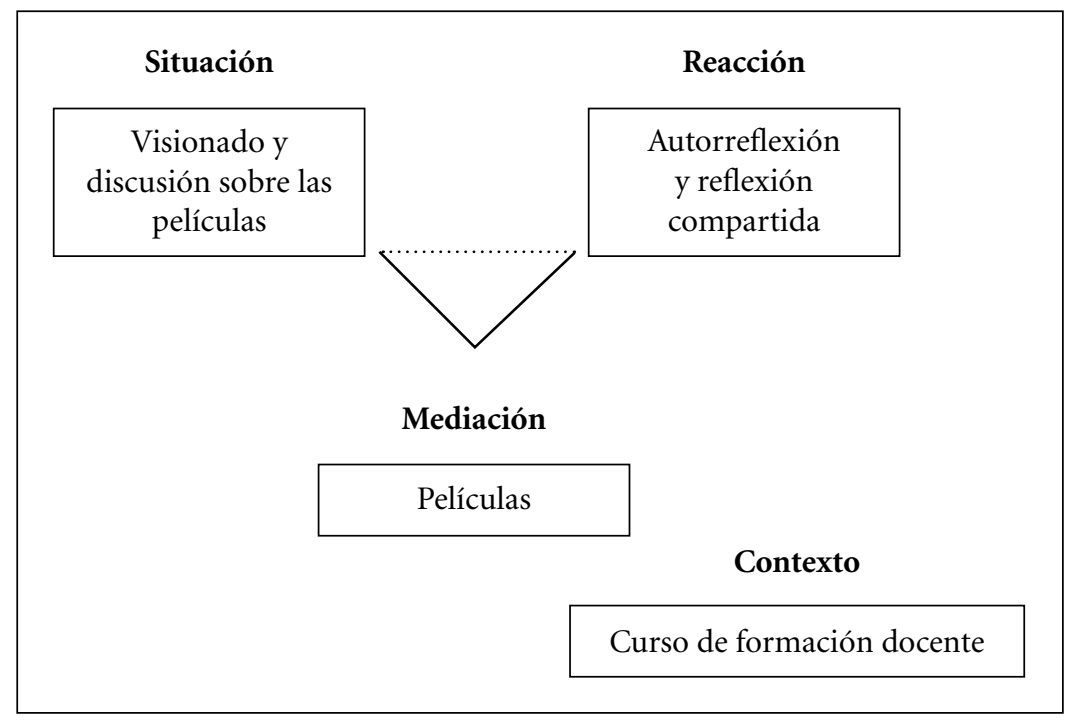

Figura 2. Representación del proceso de mediación con filmes. (Mayrink, 2007)

La película, por tanto, al ejercer su papel de signo, conduce a los alumnos "a una estructura específica de comportamiento que se destaca del desarrollo biológico y crea nuevas formas de procesos psicológicos enraizados en la cultura" (Vygotsky, 1930/1998, p. 54). Vale recordar que Vygotsky se refiere a estos procesos psicológicos como superiores. Para él, las características principales de las funciones intelectuales superiores son la conciencia reflexi- 
va y el control deliberado (Vygotsky, 1934/1999, p. 112). Asimismo, el autor destaca que "todas las funciones psíquicas superiores son procesos mediados, y los signos constituyen el medio básico para dominarlas y dirigirlas. El signo mediador se incorpora a su estructura como una parte indispensable, en realidad como la parte central del proceso como un todo" (Vygotsky, 1934/1999, p. 70). Este pensamiento es extremadamente importante, pues valora el papel que la película desempeña en el desarrollo del profesor reflexivo.

\section{Reflexiones sobre la práctica pedagógica generadas por las películas: algunos ejemplos}

Para ilustrar los efectos de las películas (signos mediadores) en la formación reflexiva de docentes, presentaré algunas evidencias del proceso reflexivo vivido por trece profesores en formación inicial durante un curso ofrecido en una universidad de São Paulo ${ }^{7}$.

Resalto que fueron varios los instrumentos utilizados a lo largo del curso: textos, cuestionarios, relatos reflexivos. Sin embargo, fueron las películas las que alcanzaron mayor relieve, lo que confirma el valor de estas como gestoras de reflexiones sobre el ser profesor. Para ilustrar el efecto de las películas en el desarrollo de postura reflexiva de los profesores en formación participantes del curso, presentaré y discutiré algunos fragmentos retirados de sus trabajos escritos ${ }^{8}$. Los ejemplos seleccionados están relacionados con las películas citadas anteriormente: Cadena de Favores y Papá Canguro.

\section{Película 1. Cadena de Favores}

El trabajo 9 elaborado por el grupo que eligió y analizó la película Cadena de Favores presenta evidencias de que los estudiantes construyeron reflexiones sobre diferentes temas, de orden teórico y práctico, relacionados con el quehacer docente. El primero de ellos se refiere a la aprehensión de la teoría de aprendizaje que subyace a la propuesta del profesor protagonista de la película. El texto elaborado por los alumnos trae indicios de que el filme Cadena de Favores provocó su reflexión sobre los principios del abordaje Socio-HistóricoCultural de Vygotsky. Ello se nota en los fragmentos marcados en bastardilla que, aunque no hagan una referencia explícita al psicólogo y a sus trabajos, señalan su comprensión de la educación como un proceso que va más allá del espacio escolar, que entiende las relaciones sociales como esenciales para la constitución del individuo:

El profesor hace una pregunta pertinente a los alumnos: “¿Qué es lo que el mundo espera de ustedes?” Con esta formulación, el profesor saca a los alumnos del aula. Él muestra que lo que importa no es el presente, sino el futuro.

Esta película es diferente de las que hemos visto en el aula durante el semestre, porque el profesor no enseña solo su disciplina, sino que da una clase que puede servir para siempre a los alumnos. A él no solamente le 
preocupa la formación académica de sus alumnos, sino también la formación del individuo. Por lo general, a los profesores solo les preocupa pasar el contenido.

El hecho de que el profesor pidiera a los alumnos que buscaran en el diccionario las palabras que desconocían, evidencia que el profesor no está ahí sólo para responder a todas las preguntas. De esta forma los alumnos aprenden a investigar y ciertamente aprenden mucho más cuando buscan que cuando el profesor les da la respuesta de inmediato. Él despierta el interés de los alumnos. Aparte de esto, les da la oportunidad para que hablen, para que expresen sus ideas desde el primer momento.

En esta película pudimos observar muy bien el intercambio que se generó entre el profesor y el alumno. Se dio la interacción necesaria para que existiese este intercambio. Aparte de este intercambio, pudimos apreciar la interacción con el medio en que ellos vivían.

En estos mismos fragmentos podemos verificar el cuestionamiento de los estudiantes en cuanto a las diferentes posturas y acciones de algunos profesores. Critican al profesor contenidista, al afirmar que, "por lo general, a los profesores sólo les preocupa pasar contenidos"; aprecian al profesor co-participante, que interactúa con los alumnos y colabora como par más competente en la construcción de sus conocimientos ("En esta película pudimos observar muy bien el intercambio generado entre el profesor y el alumno"), y valoran al profesor desafiador y mediador del proceso de aprendizaje, al destacar que:

El hecho de que profesor pidiera a los alumnos que buscaran en el diccionario las palabras que desconocían, evidencia que el profesor no está ahí sólo para responder a todas las preguntas. De esta forma los alumnos aprenden a investigar y ciertamente aprenden mucho más cuando buscan que cuando el profesor les da la respuesta de inmediato. Él despierta el interés de los alumnos. Aparte de esto, les da la oportunidad para que hablen, para que expresen sus ideas desde el primer momento.

\section{Película 2. Papá Canguro}

Lo primero que llama la atención en el trabajo elaborado por el grupo que analizó esta película es la evidencia de que tomaron conciencia de su función de signo mediador de la reflexión, lo que se verifica en este comentario:

La película no es vista como una realización volcada a la cuestión del profesor en sí, sino solo como una comedia estadounidense más. Sin embargo, logramos observar algunos aspectos positivos sobre el asunto profesor/ educación en esta película. 
Además, el grupo identificó diferentes temas que emergieron del filme y que provocaron su reflexión: responsabilidad, escuela y proceso enseñanza-aprendizaje:

Después de que Charlie y Phil abren la guardería, se dan cuenta de que organizar una escuela no es tarea fácil, exige mucha responsabilidad; a pesar de cuidar únicamente niños (menores de 6 años), se percatan de que es necesario estimularlos (proceso de enseñanza-aprendizaje) (...). En esta parte de la película colocamos la cuestión de la "responsabilidad y escuela: lugar en que el alumno puede desarrollarse integralmente" (es necesario que haya condiciones favorables entre los alumnos y la escuela, como sistema, en donde puedan trabajar con las áreas: cognitiva, afectivo-emocional, motora, social, etc.), vale decir, la escuela debe ser un lugar de encuentro favorable para ambas partes: alumno, institución y profesor, no estar únicamente preocupada del lado social y profesional de los alumnos.

La mayor conciencia de la importancia de establecer relaciones entre teoría y práctica también se observa en el trabajo de este grupo, que buscó fundamentar el análisis de la película con lecturas que realizaron de forma autónoma:

Entonces, Charlie y Phil conversan con los niños para saber lo que les gustaría aprender. Los chicos los escuchan; cada niño tiene su opinión. Dentro de lo posible, los van agradando a todos. Esto correspondería al proceso de alfabetizar y ser alfabetizado: cuando "profesor y alumno en el aula comienzan a desarrollar sus actividades, ambos están involucrados en un proceso de trabajo" (Neidson Rodrigues. Por uma nova escola, p. 60); profesor y alumno tienen el derecho a equivocarse y de saber lo que puede ser progresivo o no. Lo que ocurre muchas veces es que la escuela acaba siendo un lugar de divergencia entre alumnos, profesores y el propio sistema, porque la escuela no tiene este proyecto de poder desarrollarse de modo integral.

Cabe destacar además el puente realizado por el grupo entre la película (que, según se vio, presenta un mundo que no es exactamente igual al mundo en que se vive) y la realidad que los alumnos conocen. Esa relación permite que vean el propio mundo de manera crítica y puedan interpretarlo:

Lo que pasa mucho hoy en día (sobre todo en escuelas particulares) es justo lo que se relata en el párrafo anterior, y esta es la filosofía de la escuela de la Sra. Harridan (película), una escuela extremadamente rígida y tradicional, en la que los alumnos todavía no saben ni hablar y ya los están preparando para las pruebas de selección universitaria, aprenden lenguas, filosofía, etc; y no le preocupa saber lo que los niños realmente anhelan aprender, lo que necesitan y si están sintiéndose bien como están. Ella les comenta siempre a los padres que van a conocer la escuela: "Los niños son como los helechos, con adobe y un buen jardinero crecerán hasta el cielo", y "nunca es temprano 
para empezar". Los padres creen que esto es lo mejor para sus hijos; difícilmente se dan cuenta de la filosofía de la escuela, piensan que lo "tradicional" es lo mejor. Creemos que no siempre. (...) Creemos que la escuela debería tener un proyecto de integración entre alumnos, escuela y profesores, así podrían desarrollarse integralmente y el aprendizaje para los alumnos podría ser más provechoso; los alumnos también tendrían que ser capaces de pensar qué es lo mejor para ellos mismos y se volverían más críticos.

Estas últimas iniciativas del segundo grupo se pueden interpretar como un indicativo de que los alumnos ya habían avanzado más hacia el desarrollo de una conciencia crítica (Freire, 1979), si lo comparamos con las reflexiones evidenciadas en el trabajo del grupo anterior. De ahí se concluye que el proceso de formación crítico-reflexiva del profesor pasa por etapas y tiende a ampliarse en un movimiento creciente, como lo demuestra la figura de abajo:

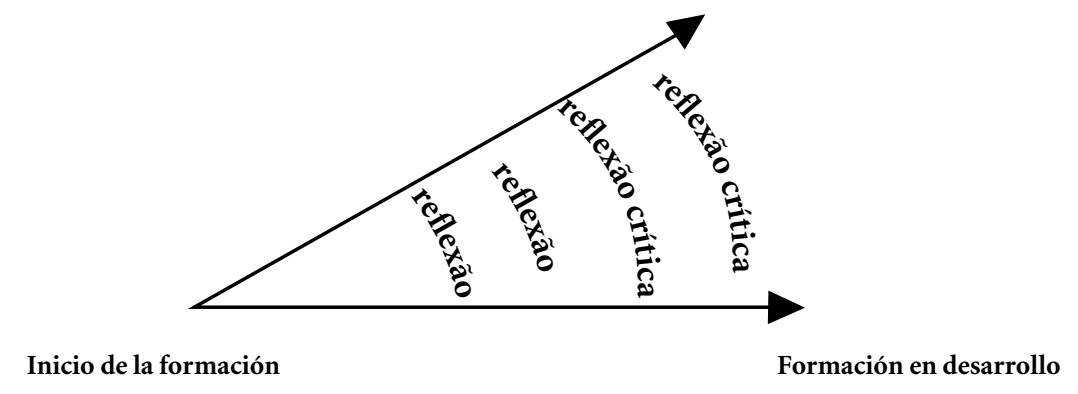

Figura 3. Ampliación de la capacidad crítico-reflexiva de los profesores.

A modo de síntesis, se puede concluir por la discusión anterior que las películas constituyen una herramienta poderosa que permite que los profesores en formación reflexionen no solo sobre su papel en el proceso de enseñanza y aprendizaje, sino también sobre las posibles relaciones entre sus conocimientos teóricos y la práctica de los profesores visualizada en la película, el conocimiento de la práctica resultante de su propia experiencia de vida y de su experiencia vicaria.

Los temas aquí presentados, identificados en los trabajos seleccionados para el análisis, ciertamente no agotan las posibilidades de relaciones y reflexiones que pueden originarse de las dos películas en cuestión. El análisis y las interpretaciones que pueden resultar del visionado de una película dependen del sujeto que se acerca a su "texto", del momento y del contexto en que se insiere este sujeto y de las experiencias acumuladas históricamente por él, experiencias a las que dirige su mirada. 


\section{Palabras finales}

La imagen y, particularmente, el filme poseen la capacidad de construir un mundo que mantiene relaciones complejas con el mundo real en el que vivimos. Constituyen por tanto un poderoso instrumento de conocimiento, pues como destaca Costa (2005, p. 152), a través de él aprendemos a ver y a conocer la realidad, aprendemos a ver el mundo y a interpretarlo (Gombrich,1971, en Joly, 1996, p. 60).

Las películas como elementos provocadores y mediadores de la reflexión crítica constituyen un recurso que puede enriquecer los programas de formación docente al contribuir a que los profesores tomen conciencia de su propia realidad y conozcan otras, aparentemente tan distantes. Propician el establecimiento de relaciones entre teoría y práctica y promueven cuestionamientos diversos que colocan en discusión sus experiencias personales, el papel de la escuela y del profesor, y la interrelación entre los diferentes elementos que conforman el proceso de enseñanza y aprendizaje: el docente, el estudiante, el contenido, la metodología, la sociedad. Asimismo, las películas pueden promover en los profesores procesos de transformación que pueden resultar en una nueva percepción de sí mismos, en la formación de su identidad y en el desarrollo de su postura crítico-reflexiva, el primer paso para un cambio aun más significativo: la transformación de la realidad que los rodea. No está demás decir que las películas que colocan la escuela, profesores y alumnos en escena constituyen un poderoso recurso para el desarrollo reflexivo de profesores que no se acaba en el cronograma y el espacio limitado de los cursos de formación, sino que se expande hacia la vida. A partir del momento en que el profesor-espectador reconoce en el filme la función de signo mediador de la reflexión, toda y cualquier película pasa a ser vista, potencialmente, como tal. Los primeros pasos, dados con la mediación del formador de profesores, pueden, por lo tanto, extenderse a muchos otros, y las películas pasan a ser parte constituyente de la formación continua y autónoma de los docentes.

\section{Notas}

1. Este texto reúne algunas de las reflexiones que integran mi tesis de Doctorado (intitulada Luzes, câmera, reflexión... formación inicial de profesores mediada por filmes), defendida en el 2007en el Programa de Estudos Pós-Graduados em Lingüística Aplicada e Estudos da Linguagem, de la Pontifícia Universidade Católica de São Paulo.

2. Schön (1992, p. 123) reconoce haber basado su trabajo en la teoría de Dewey.

3. Traducción mía.

4. Traducción mía.

5. Presento aquí una traducción de las sinopsis retiradas de las contra portadas de los videos, publicadas originalmente en portugués.

6. Para Dewey (1938/1967), la experiencia puede entenderse como conocimiento acumulado. Relacionada a esta idea está uno de los principios fundamentales de la teoría desarrollada por el filósofo: el principio de la continuidad, según el cual una experiencia prepara el camino para otra, subsecuente, dándole continuidad y permitiendo el desarrollo de una 
cadena -un continuo experiencial- que, si se mantiene, se configura como una secuencia de experiencias educativas.

7. Los textos que se presentarán corresponden a muestras de los datos recogidos en mi tesis de Doctorado (Mayrink, 2007). La investigación tuvo lugar en el curso de formación inicial de profesores que ofrecí a alumnos de la carrera de Letras y Pedagogía en una universidad de São Paulo, Brasil. Todas las clases del curso, intitulado La escuela en el cine: reflexiones sobre la práctica pedagógica a partir de filmes, fueron grabados en audio y video y los ejemplos que aquí presento corresponden a la transcripción de los datos.

8. En la fase final del curso, los alumnos se dividieron en grupos y su tarea consistió en seleccionar una película, analizarla y proponer una discusión para todos los compañeros. Posteriormente, los grupos entregaron un trabajo escrito que reunía el análisis realizado anteriormente y la discusión que se desarrolló en clase el día de su presentación.

9. Los trabajos se escribieron originalmente en portugués.

\section{Referencias bibliográficas}

Alarcão, I. (2003). Professores reflexivos em uma escola reflexiva. São Paulo: Cortez Editora. Almeida, M. J. (2001). Imagens e sons. A nova cultura oral. São Paulo: Cortez Editora. Contreras, J. (2002). A autonomia de professores. São Paulo: Cortez Editora. Costa, C. (2005). Educação, imagem e mídias. São Paulo: Cortez Editora.

Dewey, J. (1933). How we think. Lexington: D.C. Heath and Company. . (1938/1967). Experience and Education. New York: Collier Books.

Duarte, N. (2000). Vygotsky e o "Aprender a Aprender". Críticas às Apropriações Neoliberais e Pós-Modernas da Teoria Vygotskyana. Campinas: Editora Autores Associados.

Freire, P. (1979). Educação e Mudança. Rio de Janeiro: Paz e Terra.

García, C. M. (1992). A formação de professores: centro de atenção e pedra-de-toque. In Nóvoa, A. (coord.), Os professores e a sua formação (pp. 53-76). Lisboa: Publicações Dom Quixote.

Gomes, R. (2004) Elo vital: a interação espectador/filme. Disponible en http://www.facom. ufba.br/sentido/elovital.html. Consulta en 11 de mayo de 2013.

Goyes N., J. C. (2002). Horizontes de la comunicación visual contemporánea. Disponible en http://www.ucm.es/info/especulo/numero22/com_visu.html. Consulta en 07 de mayo de 2013.

Joly, M. (1996). Introdução à análise da imagem. Campinas: Papirus Editora.

Kemmis, S. (1987). Critical reflection. In Wideen, M. F.; Andrews, I. (orgs.) Staff development for school improvement. A focus on the teacher. London: The Falmer Press.

Liberali, F. C. (2010). Formação crítica de educadores: Questões fundamentais. Campinas: Pontes Editores.

Mayrink, M. F. (2007). Luzes... câmera... reflexão: formação inicial de professores mediada por filmes. Tese de Doutorado. Programa de Linguística Aplicada e Ensino de Línguas. PUC/SP. Perrenoud, P. (2002). A Prática Reflexiva no Ofício de Professor: Profissionalização e Razão Pedagógica. Porto Alegre: Artmed Editora. 
Pimenta, S. G. (2002). Professor Reflexivo: construindo uma crítica. In Pimenta, S. G. y Ghedin, E. (orgs.) O professor reflexivo no Brasil: gênese e crítica de um conceito. (pp. 1752). São Paulo: Cortez.

Schön, D. A. (1983). The reflective practitioner - How professionals think in action. New York: Basic Books.

. (1987). Educating the reflective practitioner. San Francisco: Jossey-Bass Publishers. . (1992). Formação de professores como profissionais reflexivos. In Nóvoa, A.

(coord.) Os professores e a sua formação. Lisboa: Publicações Dom Quixote.

Vygotsky, L. S. (1930/1998). A formação social da mente. São Paulo: Martins Fontes. . (1934/1999). Pensamento e Linguagem. São Paulo: Martins Fontes.

Zeichner, K. M. (1993). A Formação Reflexiva de Professores: Idéias e Práticas. Educa.

Summary: The aim of this article is to discuss how movies could be important mediators signs for teacher training. After an initial discussion on the concept of critical-reflective training we will discuss the value of the image as one of the tools that dominate contemporary communication, and will stand the potential of movies and fiction to create opportunities for the construction of new knowledge and experiences. Also, we will discuss the role of movies as mediator signs in reflective teacher education. To illustrate the effects of such signs in the development of the reflective stance of teachers, we present some evidence of the problems faced by teachers in a course of initial training, resulting from their exposure to movies featuring teachers and students play different educational situations .

Key words: teacher training - reflection - movies - sign.

Resumo: $\mathrm{O}$ objetivo deste artigo é discutir o modo que a imagem, e mais especificamente os filmes podem constituir importantes signos mediadores da formação de professores. Depois de uma discussão inicial sobre o conceito de formação crítico - reflexiva, se discutirá sobre o valor da imagem como uma das ferramentas que predominam na comunicação contemporânea, e se destacará o potencial do cinema e da ficção em geral para criar oportunidades de construção de novos conhecimentos e vivencia de novas experiências. Além disso, se analisará o papel de signo mediador que podem desempenhar os filmes na formação reflexiva de professores. Para ilustrar os efeitos desses signos no desenvolvimento da postura reflexiva dos professores, se apresentarão algumas evidências do processo vivido por professores num curso de formação inicial, resultante da exposição de filmes protagonizados por professores e estudantes que reproduzem diferentes realidades escolares.

Palavras chave: formação de professores - reflexão - filmes - signo. 